
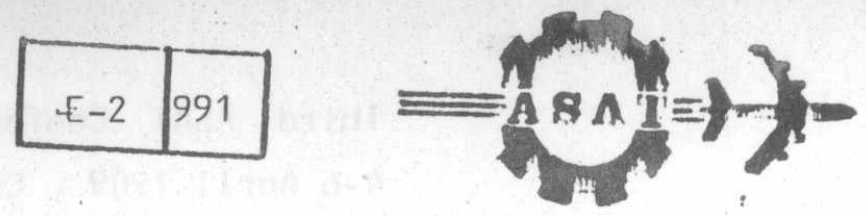

Military Jechnical College

CAIRO - EGYPI

\title{
A SIMPLIFIED APPROACH FOR STEADY-STATE ANALYSIS OF THE ISOLATED SELF-EXCITED INDUCTION GENERATOR
}

\author{
H. K. Ahmad, * F. Bendary, * M. A. Morsy Shanab* and O. H. Abdalla* *
}

This paper PrSTRAC : state performance of the 1 solated self-excited induction circult of feeding $R-L$ load using the conventional equivalent efflcient in analysing The approach is shown to be very operation. state performance of varlous system parameters on the steadyanalysis can have been studied. It is shown that the required to maintain to predict the terminal capacitance simulation results a constant terminal voltage. The presented such systems.

\section{Introduction:}

The capacitor self-excited induction generators are becoming attractive for generating electric power from unconventional energy sources such as wind, blogas, small hydroheads... etc., specially in 1 solated and remote areas. These 1 solated power sources may meet the needs of the local people in the absence mechanicatility grid. Since induction generators can convert speeds, they over a wlde range of rotor for critical consldered as high rellable generators equipments [1].

Such generators offer numerous advantages over synchrohous size, no separate d. c. sourcenstruction (cage rotor), reduced and above all low cost. the alr-gap depends capacitors help the statorlally on the stator current. The more and more stator tor voltage to bulld-up, hence allowing to be present in the current to flow. Some initial energy has magnet $1 \mathrm{zm}$ in the rotor or Thls can take the form of residual through the stator while form of a pulse of current e the machine is running [3].

* Military Technical College.

in University of Helwar. 
Owing to the increasing emphasis on the application of such generators, their steady-state analysis are gaining greater importance. If the terminal voltage and frequency are known, as in the case of a machine connected to an utility grid the prediction of performance is stralghtforward [7,8]. In a capacitor self-excited induction generator used as an isolated power source, both the terminal voltage and frequency are unknown and have to be computed for a given speed, capacitance, and load impedance. The analysis is complicated due to the magnetic saturation in the machine and the need to choose sultable parameters corresponding to the saturated condition. steady-state analysis of such generators has been recently reported [2-6]. References $[3,6]$ use the principle of conservation of real power and VARS. Newton-Raphson 1tteration technique has been adopted in references $[2,5]$. In reference [4] the analysis depends on the concept of operational equivalent circuit (complex frequency approach).

This paper proposes a simplifled approach for analysing the steady-state performance of 1 solated self-excited induction generator feeding $R-L$ load. The resultant equation is rewritten

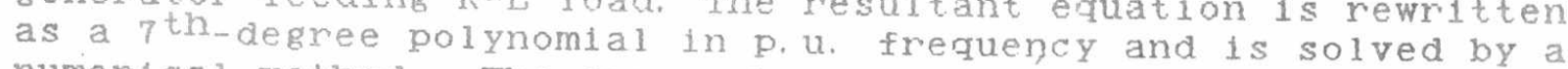
numerical method. The approach proved to be simple and elegant 1 compared with the earlier approaches. The developed computer algorithm is used in studying the effect of the variation of generator and load parameters and excltation capacitor on the generated voltage and frequency.

\section{Steady-State Analysis:}

The analysis of the capacitor self-exc1ted induction generator under steady-state operation can be made using the conventional equivalent circult of the induction machine. However, as the operating frequency of the generator varies with the driving speed and load, the equivalent circult has to be modifled as shown in Fig.1, where all the parameters are referred to the rated frequency $[6,8]$. The following assumptions are made in this analysis:

1. Only the magnetizing reactance $x_{m}$ is consldered to vary with the level of saturation, all other parameters being

11. The magnetomotive force (MMF) space harmonics and time harmonics in the induced voltage and current waveforms are ignored.

11. The core los in the machine is neglected.

The steady-state equivalent circuit shown in Fig. 1, can be simplifled as follows:

Let:

$Z_{1}=$ stator Impedance per phase

where :

$$
=\left(\left(R_{1} / F\right)+R_{L}\right)+J\left(X_{1}-X_{L}\right)
$$$$
R_{L}=R X_{C}^{2} /\left(F(R F)^{2}+\left(X F^{2}-X_{C}\right)^{2}\right)
$$$$
x_{L}=x_{C}\left(R^{2}+x\left(X F^{2}-x_{C}\right)\right) /\left((R F)^{2}+\left(X F^{2}-X_{C}\right)^{2}\right)
$$ 


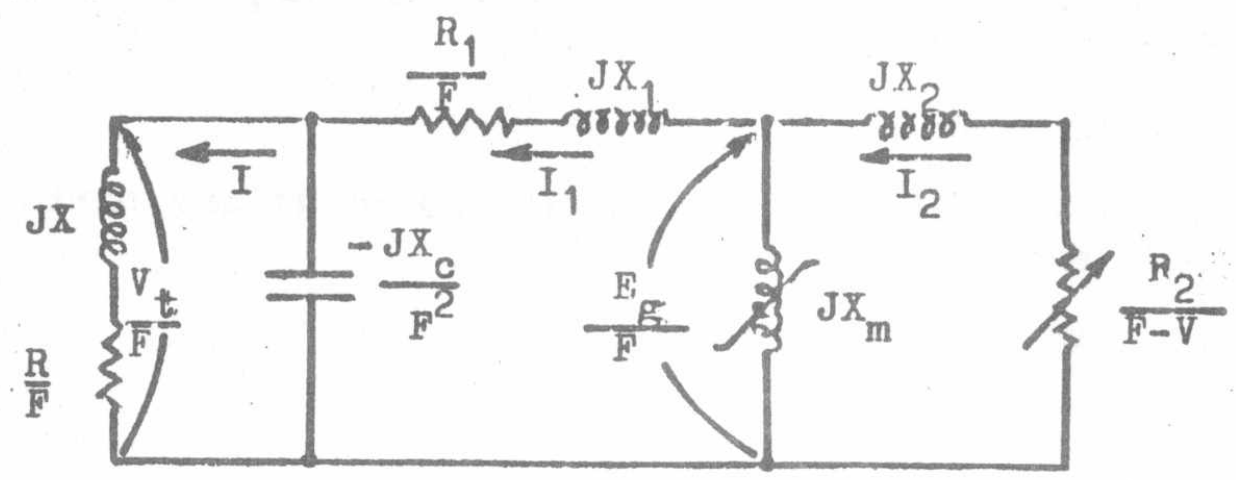

Fig:1. Per-Phase Equivalent Circuit of Induction Generator at. Excited Frequency.

and

$\begin{aligned} \mathrm{Z}_{2} & =\text { rotor Impedance per phase referred to stator. } \\ & =\left(\mathrm{R}_{2} /(\mathrm{F}-\mathrm{V})+\mathrm{J} \mathrm{x}_{2}\right)\end{aligned}$

Thus, the previous equivalent circult can be reduced to:

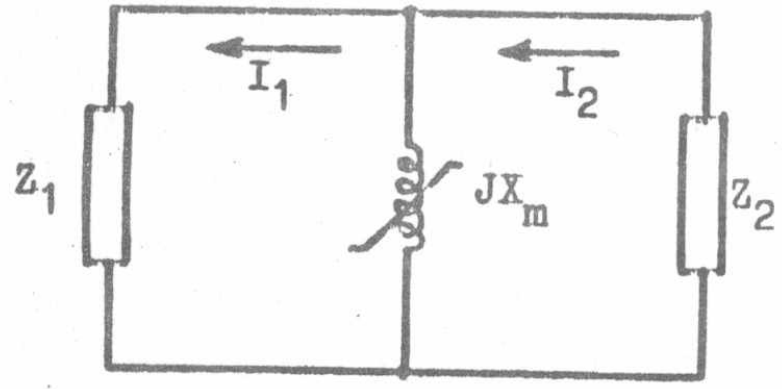

F1g.2. Reduced Equivalent circuit.

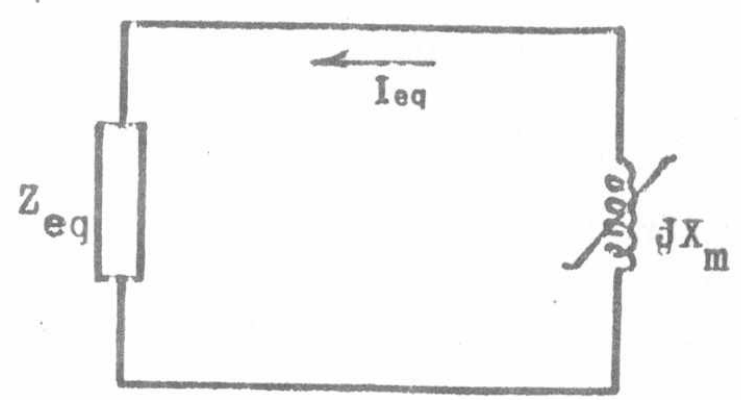

Fig.3. Simplified Equivalent Circuit.

Since the three branches in F1g.2, are in parallel, another reduction can be made by combining $z_{1}$ and $z_{2}$ into one impedance $\mathrm{Z}_{\text {eq }}$, where

$$
z_{\text {eq }}=z_{1} z_{2} /\left(z_{1}+z_{2}\right)
$$

and the equivalent circuit of F1g. 2 , reduces to that shown in F1g. 3 .

Th1s equivalent circult does not contaln any emf source or carrent sourci: Therefore, the loop equation of the current Ieq $\left(z+q+j x_{m}\right) \perp \circ q=0$ 
But, under steady-state self-excltation, I eq does not equal to zero. Therefore, from equation (6),

$$
\mathrm{z}_{\text {eq }}+j \mathrm{x}_{\mathrm{m}}=0
$$

which implies that both the real and Imaginary parts would be separately equal zero.

$$
R_{\text {eq }}+j x_{\text {eq }}=-j x_{m}
$$

From wh1ch :

$$
\begin{aligned}
& R_{\text {eq }}=0 \\
& x_{m}=-x_{e q}
\end{aligned}
$$

Since $R_{e q}$ and $X_{e q}$ are the real and imaglnary parts of $z_{e q}$ respectively, $z_{e q} c a n$ be rewritten in the form:

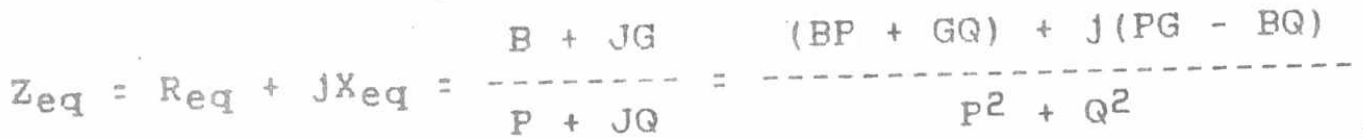

From which and referring to equations (9) \& (10)

$$
\begin{aligned}
& R_{\text {eq }}=\frac{\mathrm{BP}+\mathrm{GQ}}{\mathrm{P}^{2}+\mathrm{Q}^{2}}=0 \\
& \text { or } \mathrm{BP}+\mathrm{GQ}=0 \\
& \text { Also } \\
& \mathrm{x}_{\text {eq }}=\frac{\mathrm{GP}+\mathrm{BQ}}{\mathrm{P}^{2}+\mathrm{Q}^{2}}=-\mathrm{X}_{\mathrm{m}} \\
& \therefore \mathrm{X}_{\mathrm{m}}=(\mathrm{BQ}-\mathrm{GP}) /\left(P^{2}+\mathrm{Q}^{2}\right)
\end{aligned}
$$

where :

$$
\begin{aligned}
& B=C_{11} F^{3}+C_{12} F^{2}+C_{13} F+C_{14} \\
& G=C_{21} F^{4}+C_{22} F^{3}+C_{23} F^{2}+C_{24} F+C_{25} \\
& P=C_{31} F^{4}+C_{32} F^{3}+C_{33} F^{2}+C_{34} F \\
& Q=C_{41} F^{3}+C_{42} F^{2}+C_{43} F+C_{44}
\end{aligned}
$$

where the values of the coefficients $C_{11}$ to $C_{44}$ are given in Append1s (2).

substituting the values of B, G, P Q Q Q Q iven in equation (I to (16) Into oquation (11), rearrang1ng torms and 1 mplifying yelds:

$$
\mathrm{C}_{1} \mathrm{~F}^{7}+\mathrm{C}_{2} \mathrm{~F}^{6}+\mathrm{C}_{3} \mathrm{~F}^{6}+\mathrm{C}_{4} \mathrm{~F}^{4}+\mathrm{C}_{5} \mathrm{~F}^{3}+\mathrm{C}_{8} \mathrm{~F}^{2}+\mathrm{C}_{7} \mathrm{~F}+\mathrm{C}_{8}=0
$$


where the values of the coefflcients $C_{1}$ to $C_{8}$ are given in Append18 (3).

Equation (17) is the $7^{\text {th }}$-degree polynomial in one variable $F$ which can be solved using a numerical technique. Values of the parameters $R, x$ and $C$, and $w 1$ de speed range showed that equation (17) bas only one positive real root and three palrs of complex conjugate roots. Only the positive real root of (17) is physically acceptable. substitution by the value of $F$ in equation (12), ylelds the value of saturated magnetizing reactance $x_{m}$.

Having determined $x_{m}$ and $F$, the next step is to calculate the alr-gap voltage $\mathrm{Eg}_{\mathrm{g}}$ and the terminal voltape $\mathrm{v}_{t}$. For this purpose, one can use information regarding the variation of $x_{m}$ with the quantity $\mathrm{E}_{\mathrm{g}} / \mathrm{F}$ as mentioned in reference [2]. This information can be obtained experimentally by ariving the induction machine at synchronous speed $(\mathrm{V}=1.0)$ corresponding to the supply frequency, 1.e. $F=1.0$, and measuring the magnetizing reactance, for different input voltages at supply frequency. A curve of $E_{g} / F$ agalnst $x_{m}$ can be plotted using the experimental results. From this curve, $\mathrm{E}_{\mathrm{g} / \mathrm{F}}$ can be obtalned for the steady-state saturated values of $\mathrm{x}_{\mathrm{m}}$. knowing $\mathrm{F}$, the airgap voltage Eg can be computed.

W1th Eg: $X_{m}, F^{\prime}, X_{c}, V, R, x$ and machine parameters known, the terminal voltage $V_{t}$ l load current $I$, and power output $F_{0}$ it can be obtained from the equivalent circuit shown in Fig.1. A summary of the corresponding expressions is given as follows:

$$
\begin{aligned}
I_{1} & \left.=E_{g} /\left(F\left(R_{1}+R_{L}\right)+J\left(X_{1}+X_{L}\right)\right)\right) \\
I_{2} & =-E_{g} /\left(F\left(R_{2} /(F-V)+J X_{2}\right)\right) \\
I & =-J X_{C} I_{1} /\left(R F+J\left(X F^{2}-X_{C}\right)\right) \\
V_{t} & =I(R+J X F) \\
P_{\text {In }} & =3\left|I_{2}\right|^{2} R_{2} /(F-V) \\
T_{1 n} & =P_{1 n} / W_{S} \\
P_{\text {out }} & =3 \mid I^{2} R^{2}
\end{aligned}
$$

\section{No-LOad Condition:}

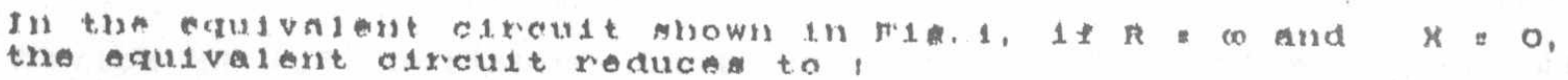




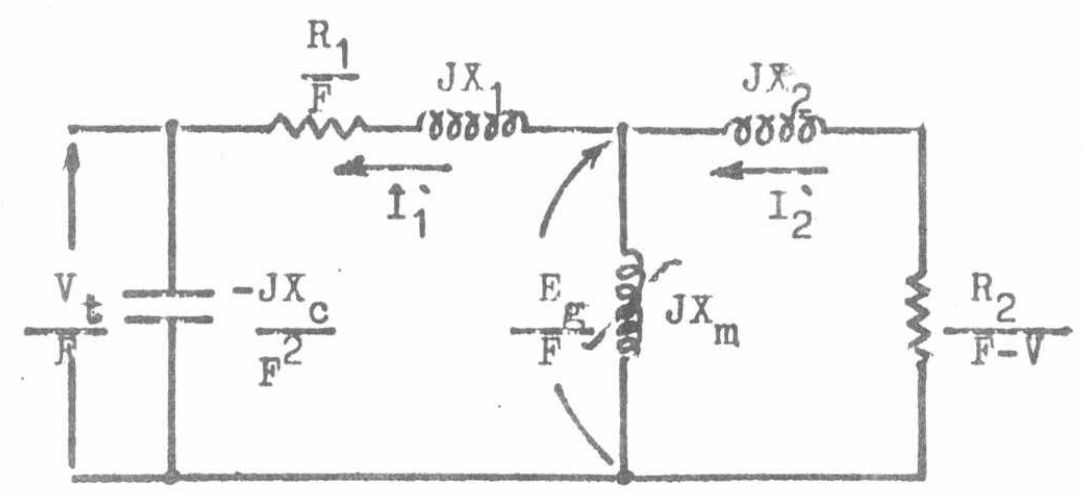

Fig.4. No-Loed Equivalent Circuit.

A similar treatment for no-load condition of operation results in the following equations:

$$
\begin{aligned}
& \mathrm{Z}_{\text {eq }}^{\prime}=\left(B^{\prime}+J G^{\prime}\right) /\left(P^{\prime}+J Q^{\prime}\right) \\
& \mathrm{X}_{\mathrm{m}}^{\prime}=\left(B^{\prime} Q^{\prime}-G^{\prime} P^{\prime}\right) /\left(P^{\prime} 2+G^{\prime} 2\right) \\
& R_{e q}^{\prime}=\left(B^{\prime} P^{\prime}+G^{\prime} Q^{\prime}\right) /\left(P^{\prime} 2+Q^{\prime} 2\right)=0
\end{aligned}
$$

from which

$$
B^{\prime} P^{\prime}+G^{\prime} Q^{\prime}=0
$$

where :

$$
\begin{aligned}
& B^{\prime}=C_{11}^{\prime} F^{3}+C_{12}^{\prime} F^{2}+C_{13}^{\prime} F+C_{14}^{\prime} \\
& G^{\prime}=C_{21}^{\prime} F^{2}+C_{22}^{\prime} F+C_{23}^{\prime} \\
& P^{\prime}=C_{31}^{\prime} F^{2}+C_{32}^{\prime} F \\
& Q^{\prime}=C_{41}^{\prime} F^{3}+C_{42}^{\prime} F^{2}+C_{43}^{\prime} F+C_{44}^{\prime}
\end{aligned}
$$

The values of the coefflcients $C_{11}^{\prime}$ to $C_{44}^{\prime}$ are glven in Appendr (4).

Substitution by the values of $\mathrm{B}^{\prime}, \mathrm{G}^{\prime}, \mathrm{p}^{\prime}$ and $\mathrm{Q}^{\prime}$ as glven in equations (31) to (34) yields the $5^{\text {th }}$-degree polynomial in F.

$$
\mathrm{C}_{1}^{\prime} \mathrm{F}^{5}+\mathrm{C}_{2}^{\prime} \mathrm{F}^{4}+\mathrm{C}_{3}^{\prime} \mathrm{F}^{3}+\mathrm{C}_{4}^{\prime} \mathrm{F}^{2}+\mathrm{C}_{5}^{\prime} \mathrm{F}+\mathrm{C}_{6}^{\prime}=0
$$

where the values of the coefficlents $C_{1}^{\prime}$ to $C_{6}^{\prime}$ are glven in Append1 $x$ (5).

To determine the value of $F$ at no-load, equation (35) is solved using the same numerlcal techulque, Having determined the value of $F$, substitution in the equation (28) ylelds the value of $x_{m}$ at no-load. since $x_{m}$ and fre determined, the calculation of the alr-gap voltage $E_{g}$, terminal voltage $v_{t}$, currents in rotor 
and stator and output power are striaghtforward, and they are
summarized below:

$$
\begin{aligned}
& I_{1}=\left(E_{g} \cdot F\right) /\left(R_{1} F+j\left(X_{1} F^{2}-X_{C}\right)\right) \\
& I_{2}=-\left(E_{g} / F\right) /\left(R_{2} /(F-V)+j X_{2}\right) \\
& V_{t}=-j X_{C} I_{1} / F \\
& P_{1 n}=-3\left|I_{2}\right|^{2} R_{2} /(F-V)
\end{aligned}
$$

\section{Machine Parameters, Results and Discussion:}

To verify the proposed analysis given in this paper, the Mawdsley's generalized machine data glven in ref. (2) is used for computation. The machine was connected as an induction machine with a 4-pole, $50 \mathrm{~Hz}$, delta-connected stator winding rated $230 \mathrm{~V}, 8.2 \mathrm{~A}$ and $2.9 \mathrm{hp}$. Theoret1cal computations are carried out in per unit, using the following particulars of the

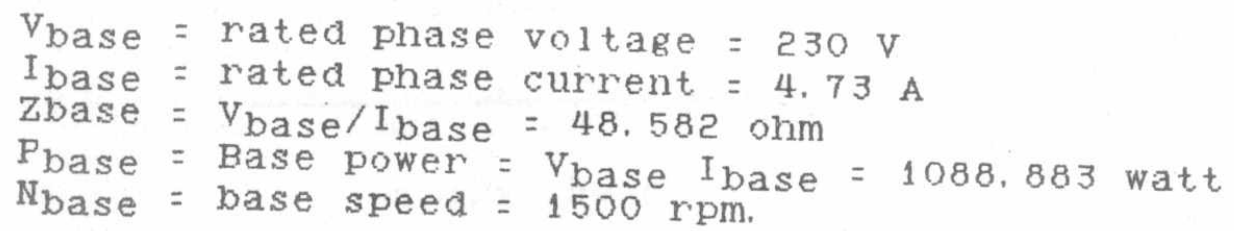

Induction machine parameters required in the analysis were determined experimentally using standard techniques.

the parameter values thus obtained were:

$$
\begin{aligned}
& R_{1}=3.0 \text { onm }(0.062 \text { p.u. }) \\
& R_{2}=3.4 \text { ohm }(0.07 \text { p. u. }) \\
& x_{1}=x_{2}=4.5 \text { ohm (0.093 p.u.) }
\end{aligned}
$$

Since we need to know the value of $E_{g} / F$ for a particular value of $X_{m}$, that value has been taken as the independent variable. The variation of $\mathrm{E}_{\mathrm{g}} / \mathrm{F}$ with $\mathrm{X}_{\mathrm{m}} \mathrm{w} 111$ be nonlinear due to magnetic saturation. To simplify the analysis the variation under the saturated region was linearized as follows:

$$
\begin{array}{rl}
E_{g} / F & =1.64673-0.3246 x_{m} 0 \leq X_{m} \leq 1.3894 \\
& =1.76562-0.4102 x_{m} \\
x_{m} & 1.3894
\end{array}
$$

These expressions are incorporated into the developed computer generators.

F1g. 5, shows calculated values of the generated voltage and frequency at no-load versus speed for $C=15,20$ and $30 \mathrm{pf}$. It is interesting to note that at f1xed value of terminal capacitance, the terminal voltage increases with speed almost linearly. Also the difference in the value of terminal capacitance does not affect the frequency. 


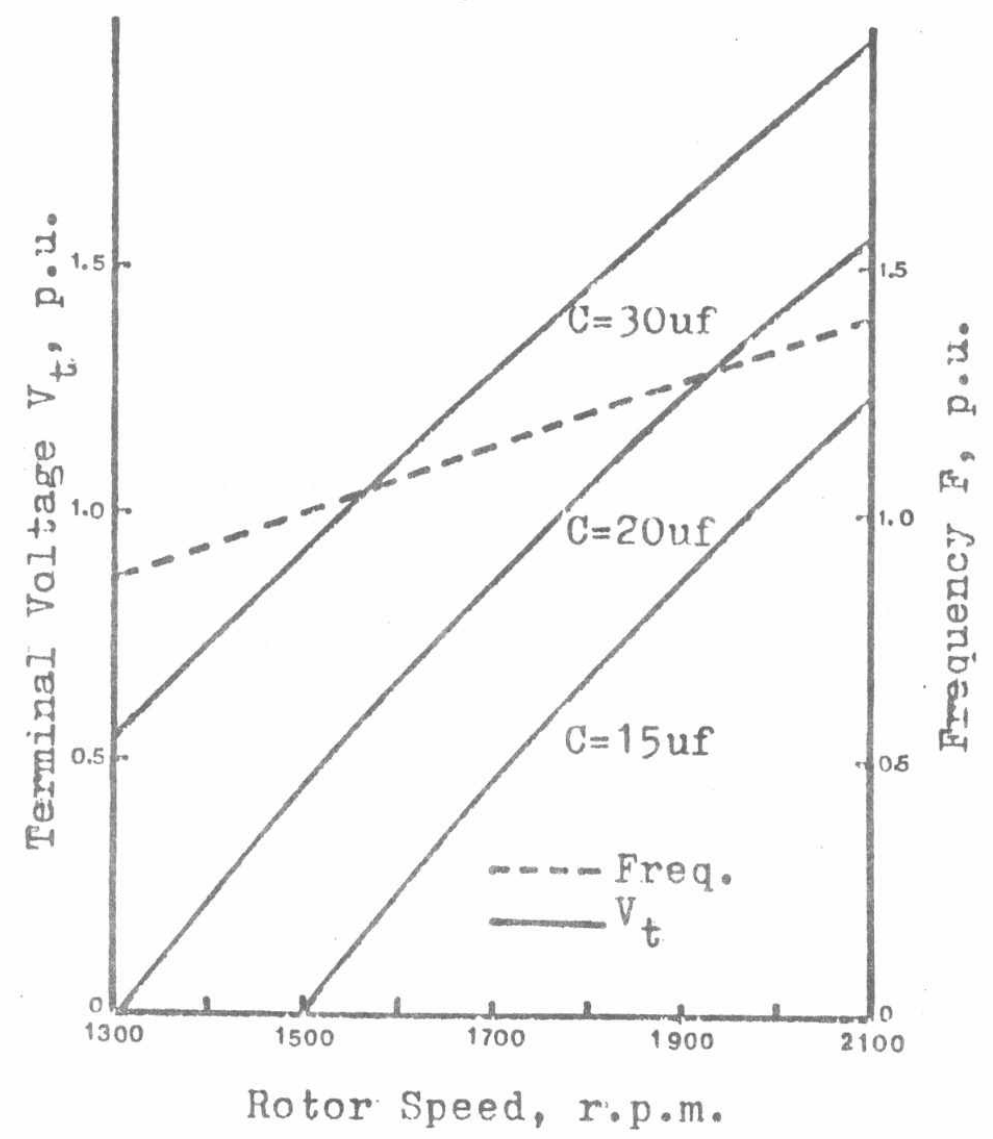

Fig.5. Generated Voltage and Frequency at Ne-Laed.

F1g. 6, indicates the calculated no-load terminal voltage and frequency as a function of terminal capacitance at constant speed. Capacitance values were chosen above the minlmum value requ1rea (which was $15 \mathrm{hf}$.) to cause self-exc1tation at $V=1$. 0 p. u. It $w 111$ be noted that at a fixed speed the terminal voltage increases with capacitance. Several runs of the computer programs showed that the frequency 1 s speed dependent and capacitance indeperdent.

Fig. 7, presents a family of load characteristics computed for various values of $\mathrm{C}$ atv $=1.0 \mathrm{p} . \mathrm{u}$. I It can be seen that the characteristics are almost parallel indicating the proportional increase of $V_{t}$ with $c$. The frequency drop with load was not very much affected by the capacitance. At 1.0 p.u. speed, c has to be varied from 40 uf to 50 uf, to provide constant terminal voltage of $1.0 \mathrm{p}, \mathrm{u}$. for output power varying from 1.0 to 1.94 P. U. .

F1g. 8, g1ves the computed load character1stics of an 1nduction generator that indicates the variation of terminal voltage with output power for a flxed C at constant speed and varylng $10 a d$ power factor. Better voltage regulation $1 \mathrm{~s}$ observed with leading p. f. loads. With lagging p. f. loads, the regulation becomes poorer, as the exc1ting capacitors must, in this case, supply the reactive load requirements, in addition to the 
magnetizing vars of the generatos. For improved voltage regulation in this case, additional shunt capacitance would be necessary.

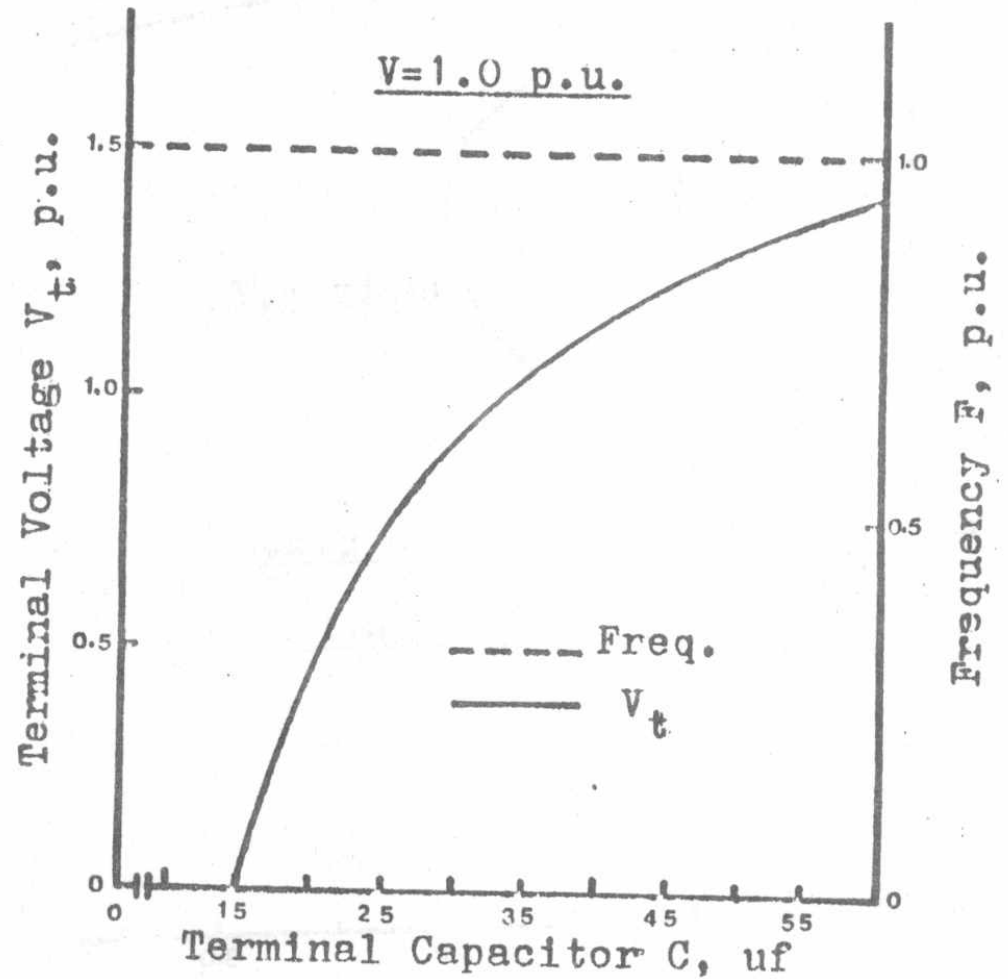

Fig.6. Generated Voltage and Frequency at No-Load.

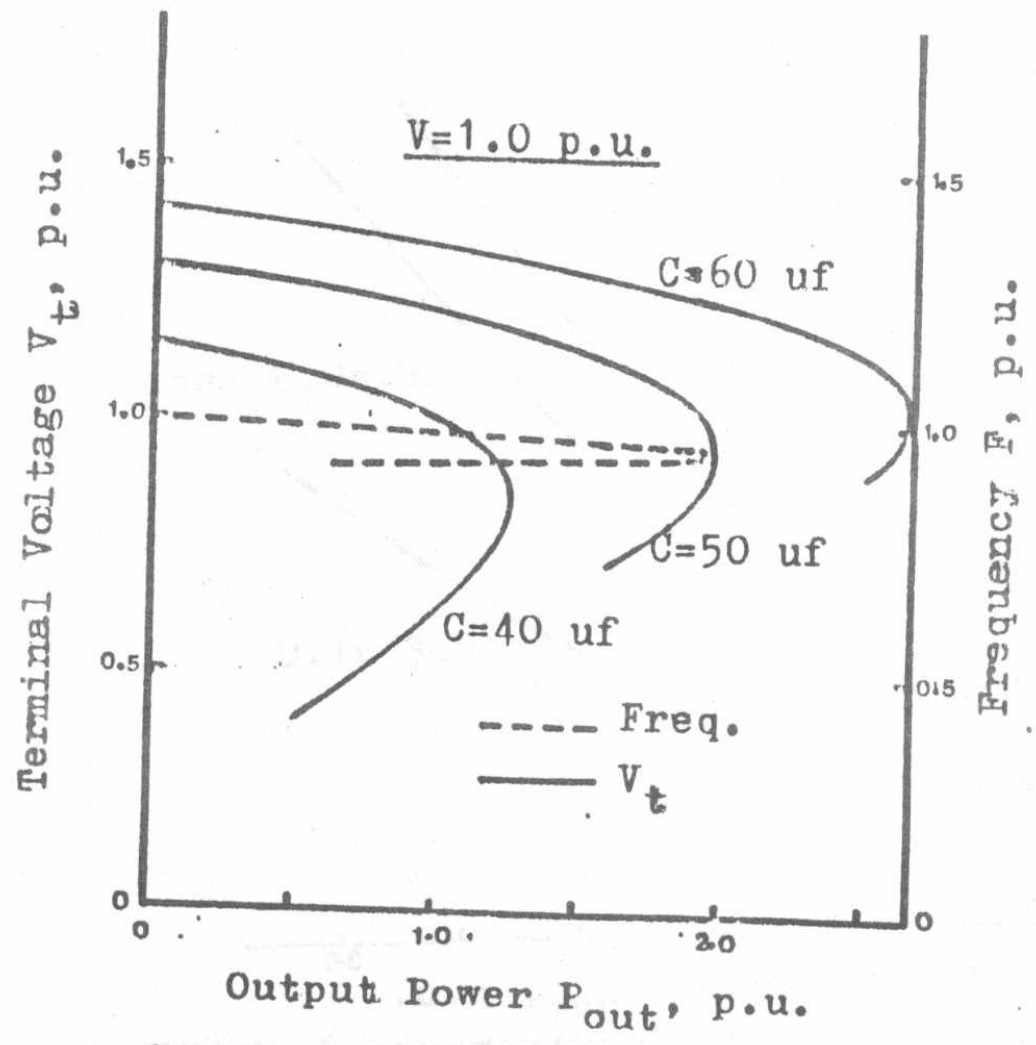

F18.7. Load Character1st1og. 


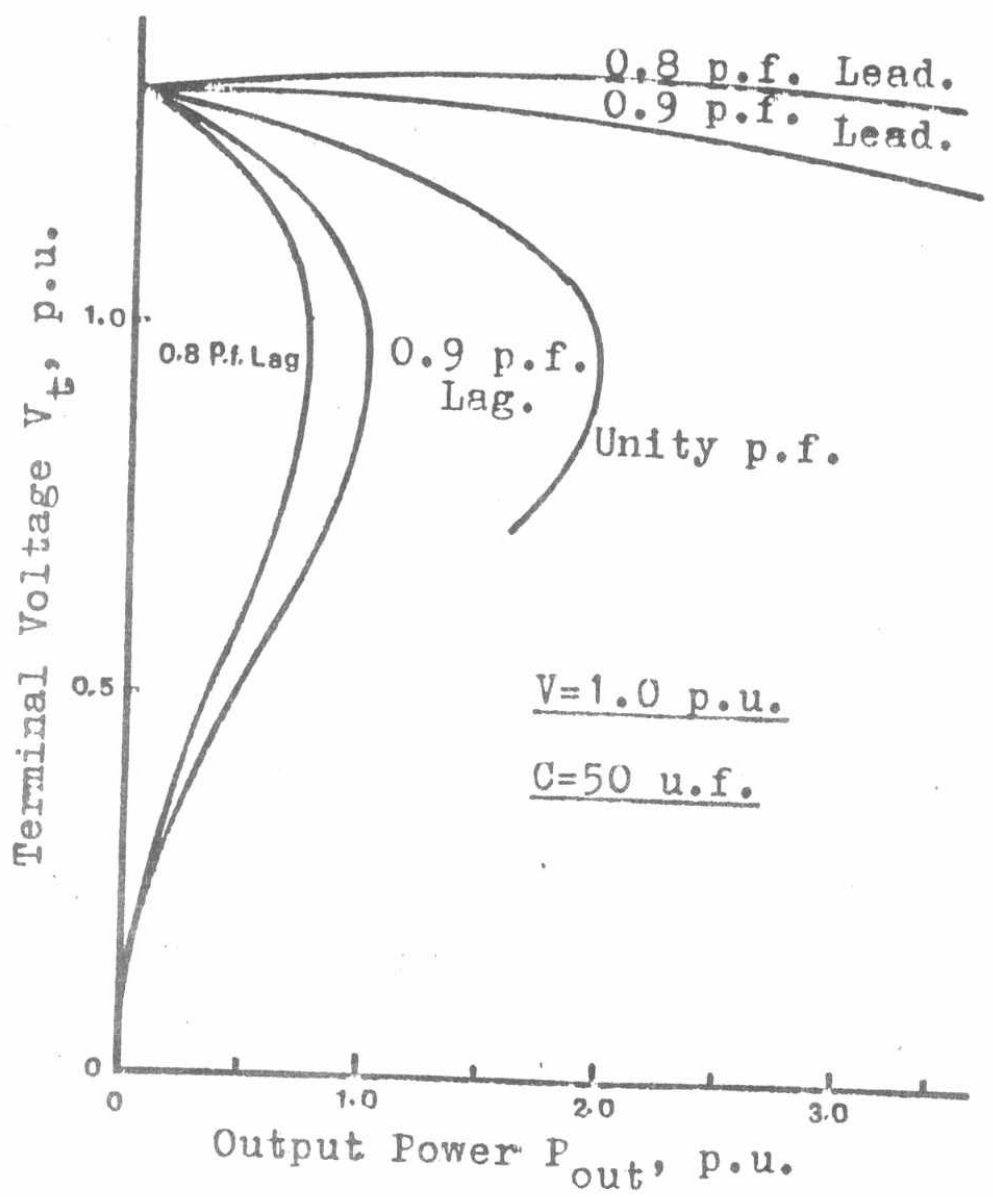

FIg.8. Effect of Laad Power Factor.

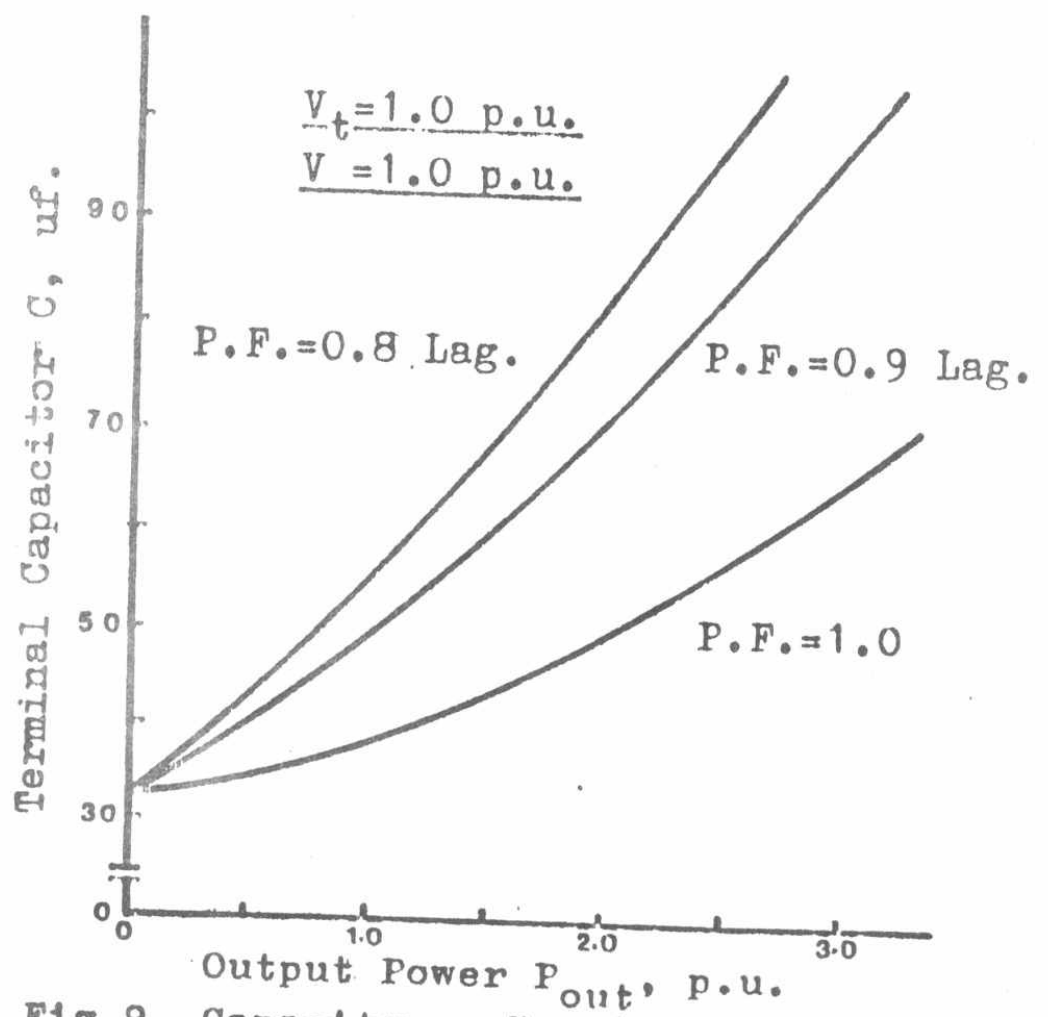

F1g.9. Capacitance Requirements to Malntain a Const. $v_{t}$ Under Var. Induct. Load. 
F1g.9, shows the effect of load power factor on the value of capacitance $C$ in order to maintain a constant terminal voltage of 1.0 p.u. at a speed of 1.0 p.u. From this figure it is clear that the requirement of terminal capacltance from no load to output power of 2,0 p. u, at 0 , \& power factor 1 agging lies in the range of 32,7 to 82.5 uf corresponding to a speed of one per unit.

\section{Conc1usion:}

A new approach for the steady-state allalysis of a capacitor self-exc1ted induction generators feeding a general impedance load has been developed. The developed computer algorlthm for computing the roots of $\mathrm{n}^{\text {th }}$-degree polynomial and prediction of performance brings out the elegance of the proposed approach. The algorithm was used in studying the effect of the variation of generator and load parameters and excitation capacitor on the generated voltage and frequency at no-load and full-1oad.

Families of characteristics, showing the effect of various system parameters, are presented. As these rurves are presented in per unit values, they may provide guldelines for appropriate design of the system. Varlation of capac1tance with load to malntain constant terminal voltage has heen also determined. Th1s w111 help in developing sultable voltage regulator. The results obtalned ind1cate that capacitance requirement increases w1th decreasing speed, load impedance and $p, f$. (1agging loads).

Such steady-state analysis of induction generators, would not only fac1litate the performance computation under alfferent load situations, but also would be useful from both the design and operational point of view.

\section{Reterences:}

1. Ch1rgw1n, K, H, and Gtratton, L. J, : "Yardanle-speed Constant-Frequency Induction Generator system for Alrcraft", Trans, AIEE, V01,78, PP. 304-310, 1959.

2. Hurthy, E. S., Mal1k, O.P. and Tandon, A, K. "Analysis of Self-Exc1ted Induction generators", IEE Proc., Vol. 129, Pt, C, No, 6, PP, 260-265, Nov, 1982 .

3. Quazene, L. and Mcpherson, G. "Analysis of the Isolated Induction generator", IEEE Trans, on PAS, Vo1. PAS-102, No, 8, PP, 2793-2798, Aug, 1983.

4. Tandon, A. K., Murthy, S, S, and Berg, G. J. : "Steady-state Analysis of Capacitor self-Exc1ted Induction Generators", IEEE Trans, on PAG, Vol, PAS-103, No, 3, PP. 612-618, 19ar, 1984.

5. Mal1K, H. H. and Haque, G. E. : "Gteady-gtate Analysis and Performance of an Isolated self-Exc1ted Induction Generator", IEEE Trans, on Energy conversion, Vo1. Ec1. No. 3, PP, 134-140, Eep, 1986.

6. Ammasa1gounden, $\mu$, subblah, $\mu$, and Rrs snnamurthy, B. E. "Wind-Driven self-Ercited pole-changing Induction generators", IEE Proc, Vo1.135, Pt. B, No, B, PP, s1s321. Sep. 1986 . 
7. Alger, P. L. : "Induction Machines", Gorden and Breach, 1970.

8. Say, H. G. : "Alternating cursent Machines", New York, John W1ley \& Sons, 1976.

\section{Append18 :}

\section{1. L1st of principas symboles:}

$R_{1}, X_{1}$ stator resistance, learage reactance per pluase.

$R_{2}, X_{2}$ potor resistance, leakage reactance per phase (referred to statorl.

$x_{m} \quad$ lsagetizing reactance per puase.

$x_{c} \quad$ Reactance of terminal capacitor $c$ per phase.

$R$, $X$ Load resistance, reactance per phase.

$F, V$ Per-unit frequency and speed respectively.

$\mathbf{E}_{\mathrm{g}}$ Alr-gap voltage per phase.

$v_{t}$ Terminal voltage per phase.

I 1 stator current per phase.

I2 Rotor current per plase.

I Load current per phase.

Pin Total input power.

Pout Total output power.

Ws synch. speed in mechanceal rad./sec.

Tin Total input Torque.

7. 2. Coefficients of Equations (13) to (19):

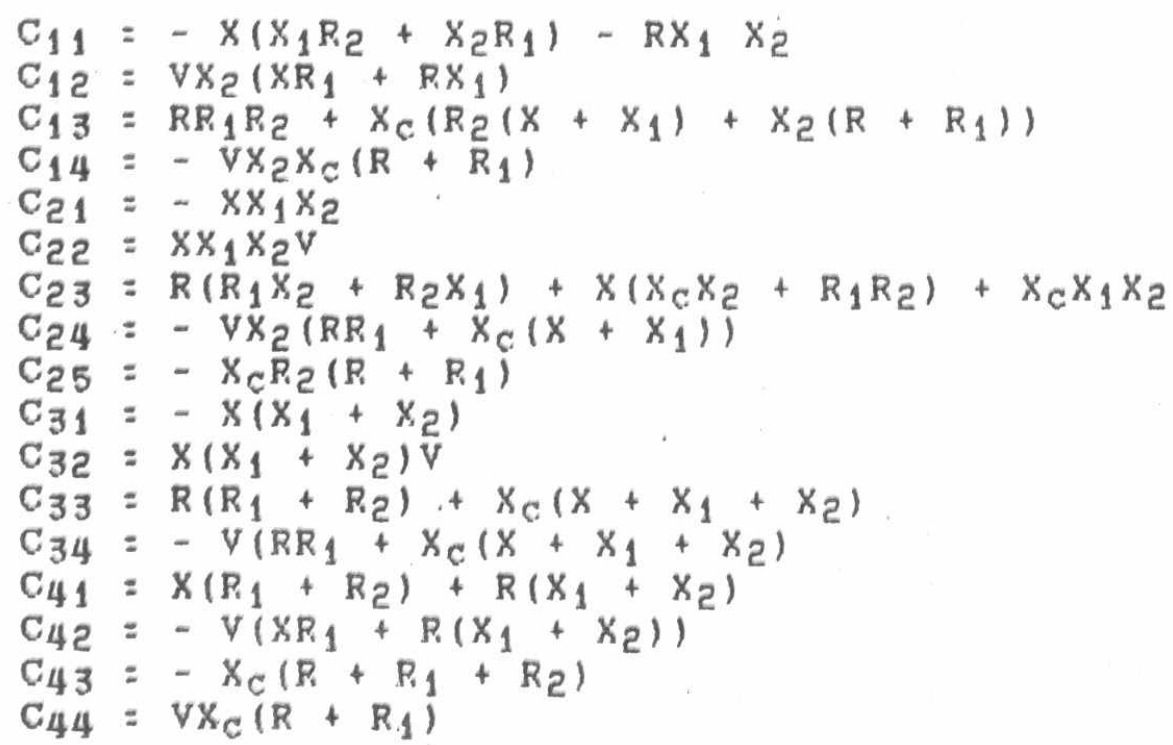

7. 3. Coefficients of Equation (17): 
$C_{7}=C_{14} C_{34}+C_{25} C_{43}+C_{24} C_{44}$
$C_{8}=C_{25} C_{44}$

7. 4. Coefficients of Equations (31) to (34):

$C_{11}^{\prime}=-x_{1} x_{2}$

$C_{12}=V_{12} X_{2}$

$C_{13}=R_{1} R_{2}+x_{2} x_{c}$

$C_{14}=-\mathrm{V}_{2} \mathrm{X}_{2} \mathrm{X}_{\mathrm{C}}$

$C_{21}=R_{1} x_{2}+R_{2} x_{1}$

$\mathrm{C}_{22}=-\mathrm{V} \mathrm{R}_{1} \mathrm{X}_{2}$

$\mathrm{C}_{23}=-\mathrm{R}_{2} \mathrm{~K}_{\mathrm{C}}$

$C_{31}=R_{1}+R_{2}$

$C_{32}=-V R_{1}$

$C_{41}=x_{1}+x_{2}$

$C_{42}=-V\left(x_{1}+x_{2}\right)$

$c_{43}=-x_{c}$

7.5. Coefficients of Equation (35):

$C_{1}^{\prime}=C_{31}^{\prime} C_{11}^{\prime}+C_{21}^{\prime} C_{41}^{\prime}$

$G_{2}=G_{31} d_{12}+C_{32} C_{11}^{\prime}+C_{21}^{\prime} C_{12}^{\prime}+C_{22}^{\prime} C_{41}^{\prime}$

$C_{3}=C_{31} C_{13}+C_{32} C_{12}+C_{121}^{\prime} C_{43}+C_{22}^{\prime} C_{42}^{\prime}+C_{23}^{\prime} C_{41}^{\prime}$

$C_{4}=C_{31} C_{14}+C_{32}, C_{3}+C_{21} C_{44}+C_{22} C_{43}+C_{23} C_{42}$

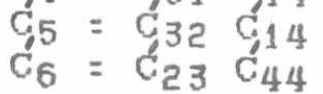

